\title{
Fatigue damage and life evaluation of thick bi-material double strap joints for use in marine applications
}

\author{
Rahul Iyer Kumar ${ }^{1}$, Pankaj Jaiswal ${ }^{1}$, and Wim De Waele ${ }^{1}$ \\ ${ }^{1}$ Universiteit Gent
}

December 1, 2021

\begin{abstract}
The present-day interest in the use of composite-steel joints in primary marine applications requires an in-depth knowledge of the fatigue performance of thick adhesive joints. This paper reports on experimental tests, quasi-static and fatigue, performed on unaged and aged bi-material double strap joints with thick adhesive bondlines. The specimens are monitored by Digital Image Correlation and Infrared Thermography techniques to evaluate the types and extent of damage that occur in the joint during fatigue loading. The S-N curve of the aged joint is evaluated along with it's fatigue limit. It is found that the unaged specimens fail due to cohesive damage, hackles and disbond at the adhesive-adherend interface and the aged specimens failed due to delamination within the composite. The specimens that survived fatigue loading showed similar residual strength as specimens that were not fatigue loaded.
\end{abstract}

\section{Hosted file}

Fatigue2021_Rahul.pdf available at https://authorea.com/users/448867/articles/547565-fatiguedamage-and-life-evaluation-of-thick-bi-material-double-strap-joints-for-use-in-marineapplications

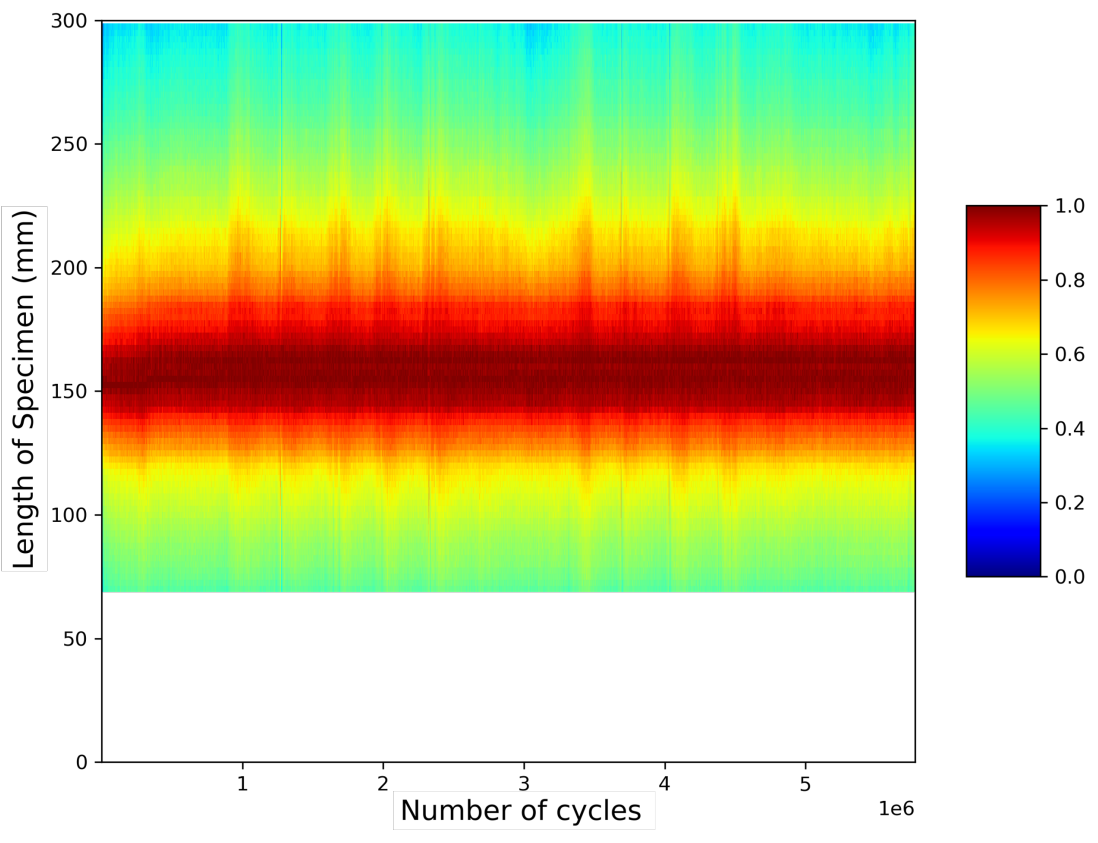




$$
\text { |ll| }
$$



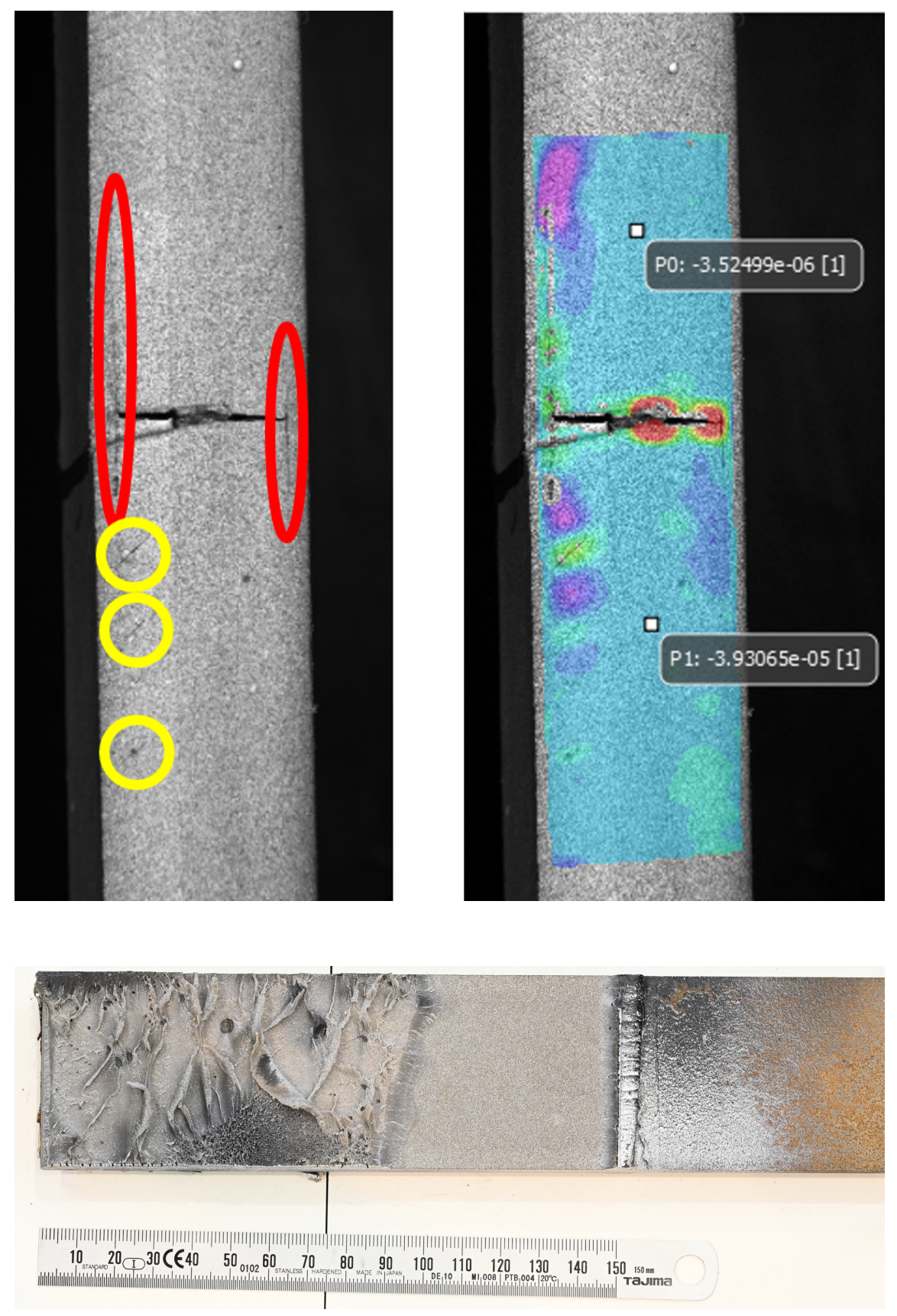

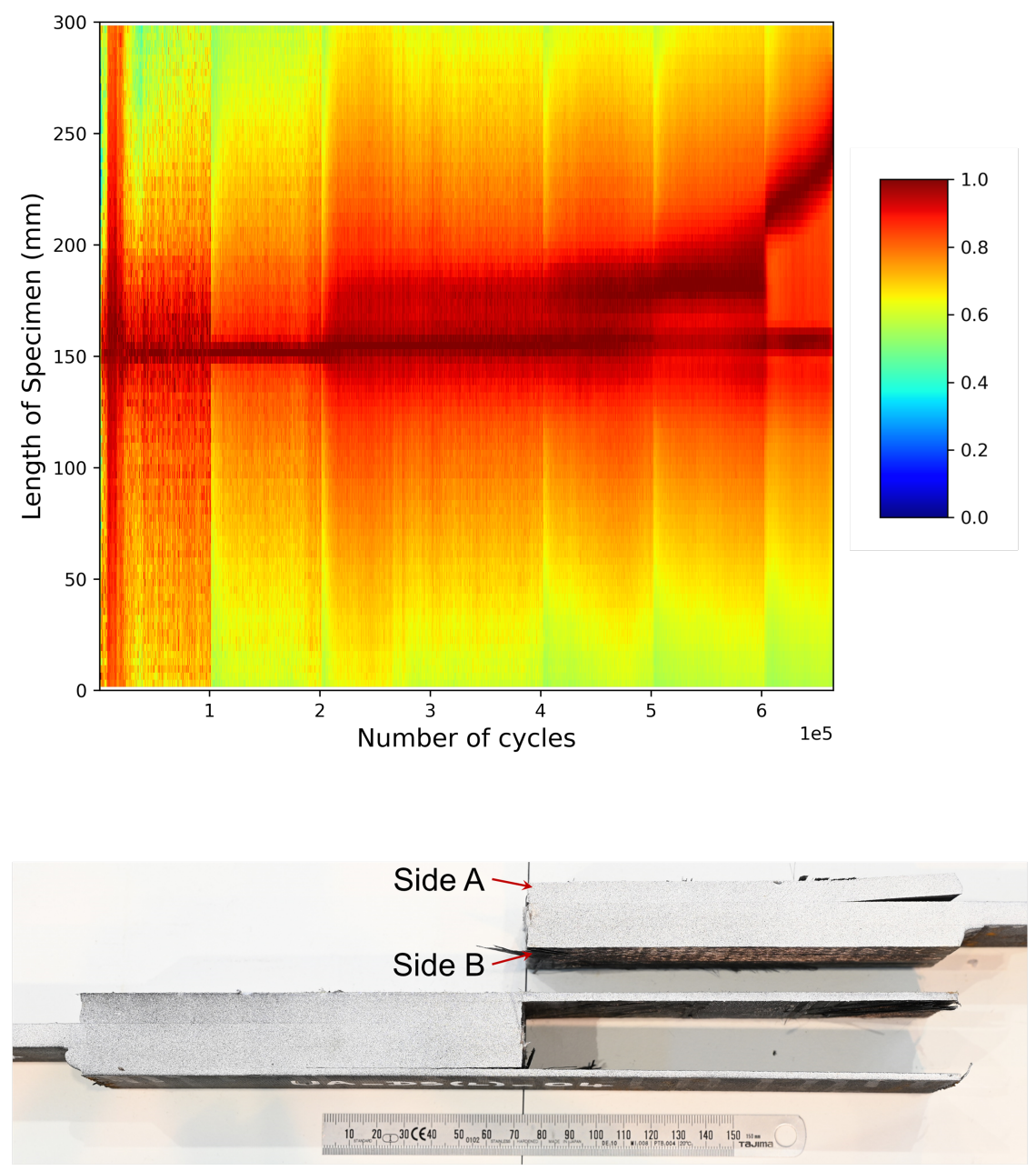

(i)

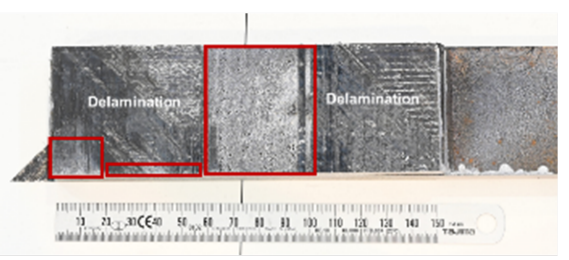

Side A

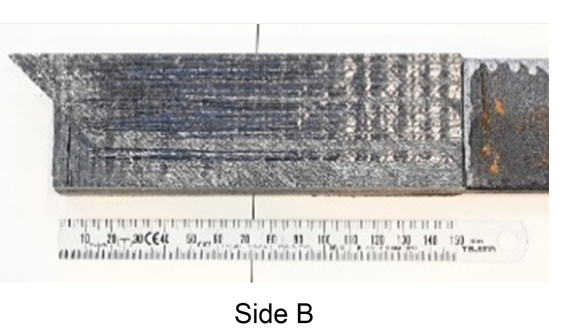

(ii) 

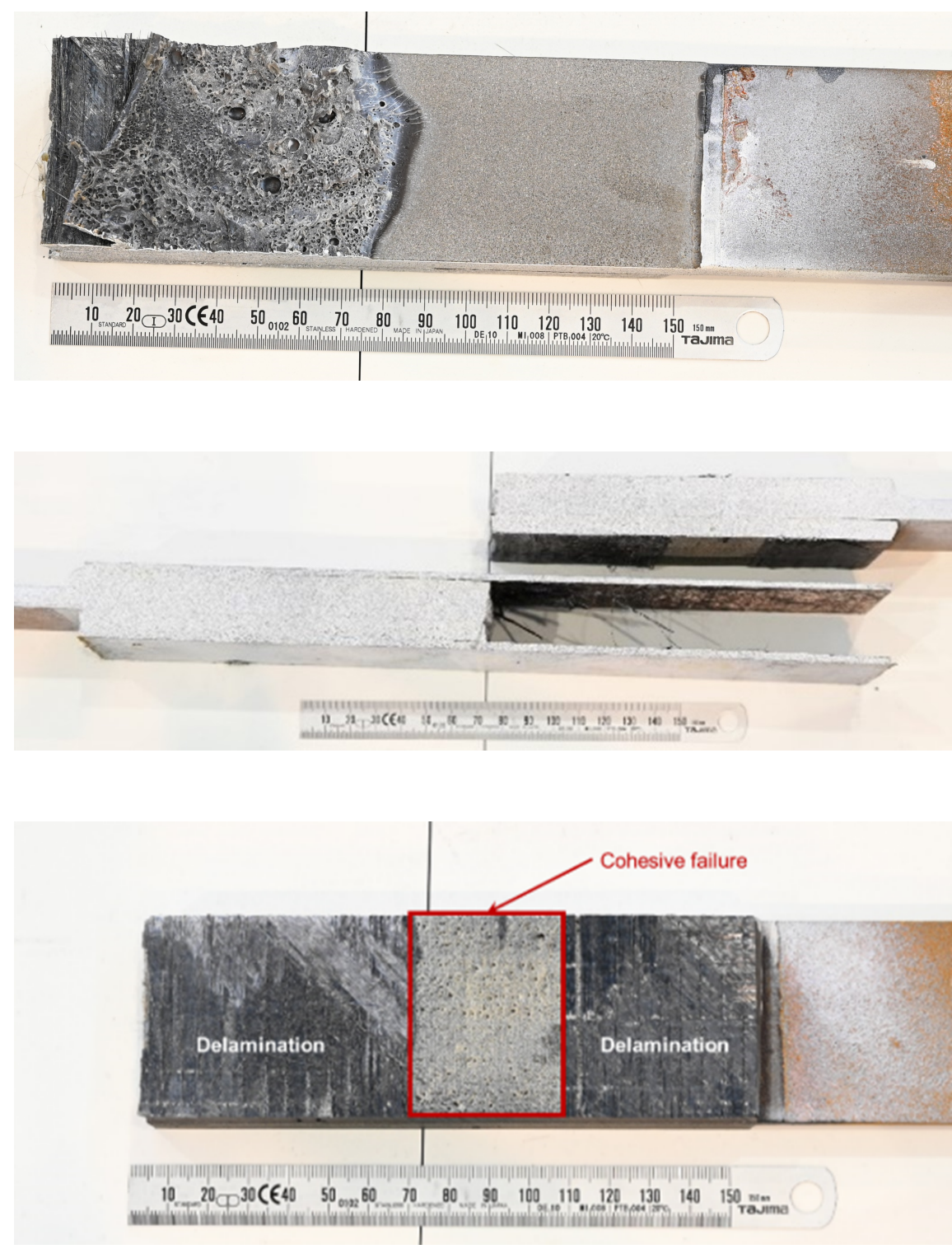

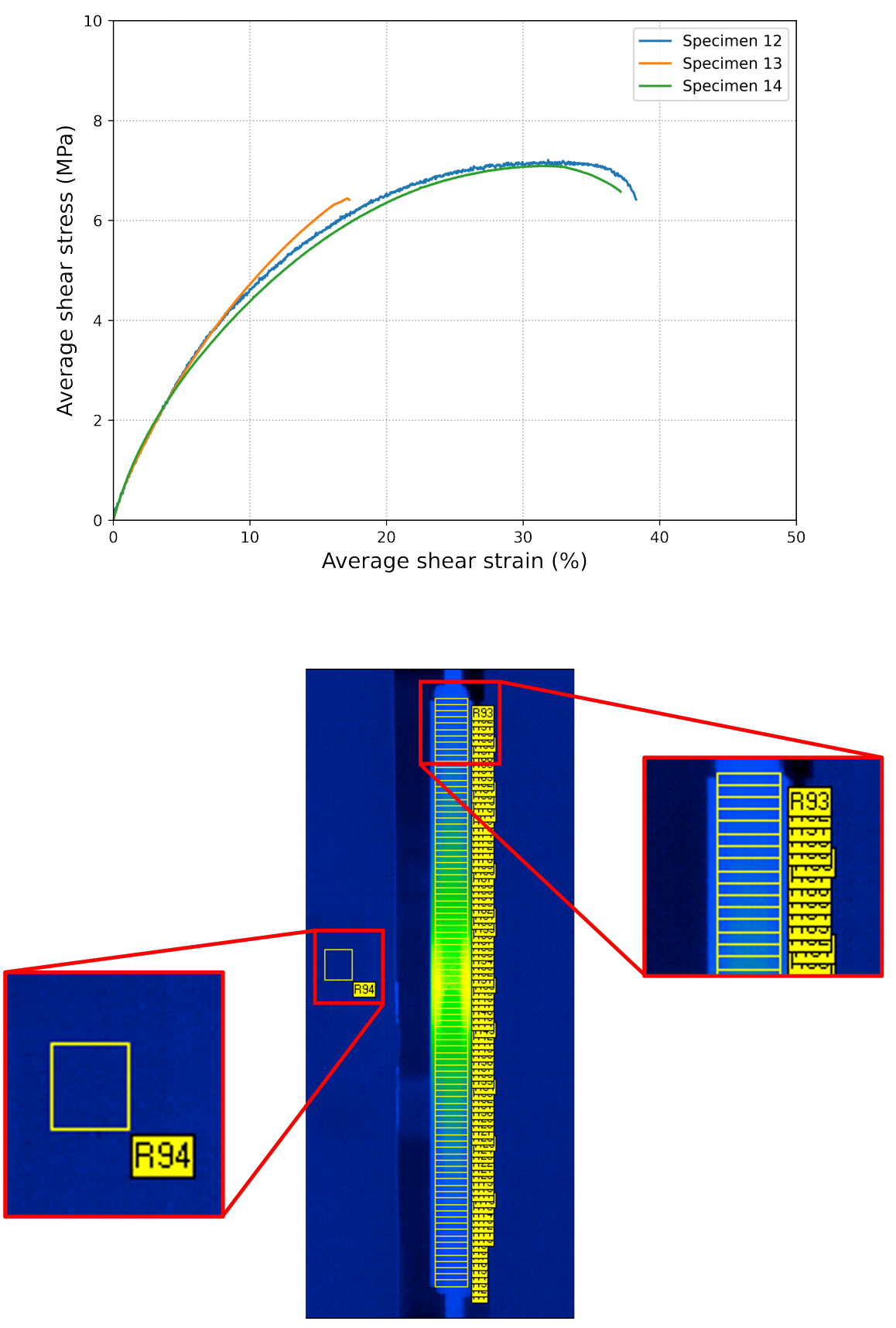

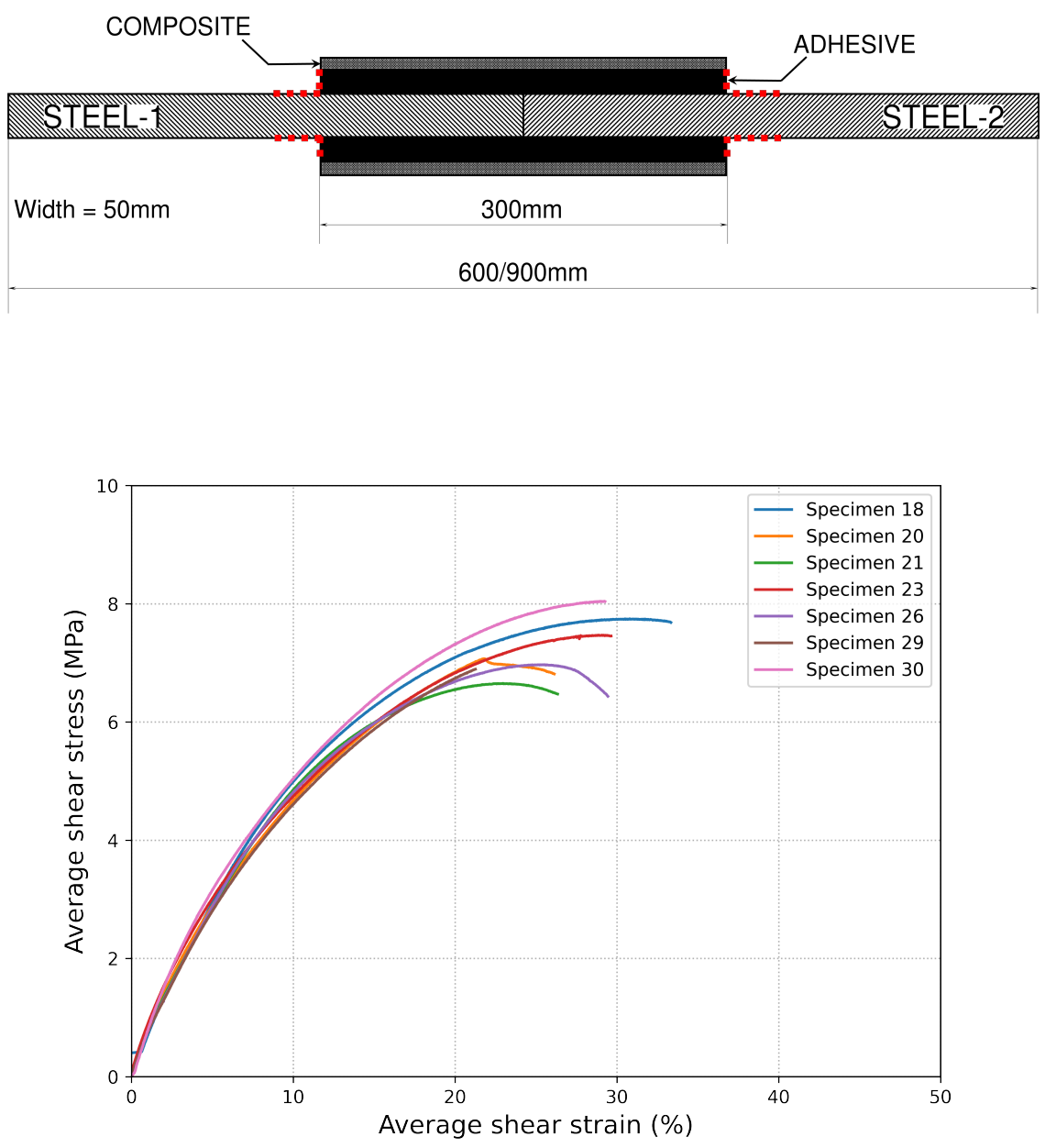


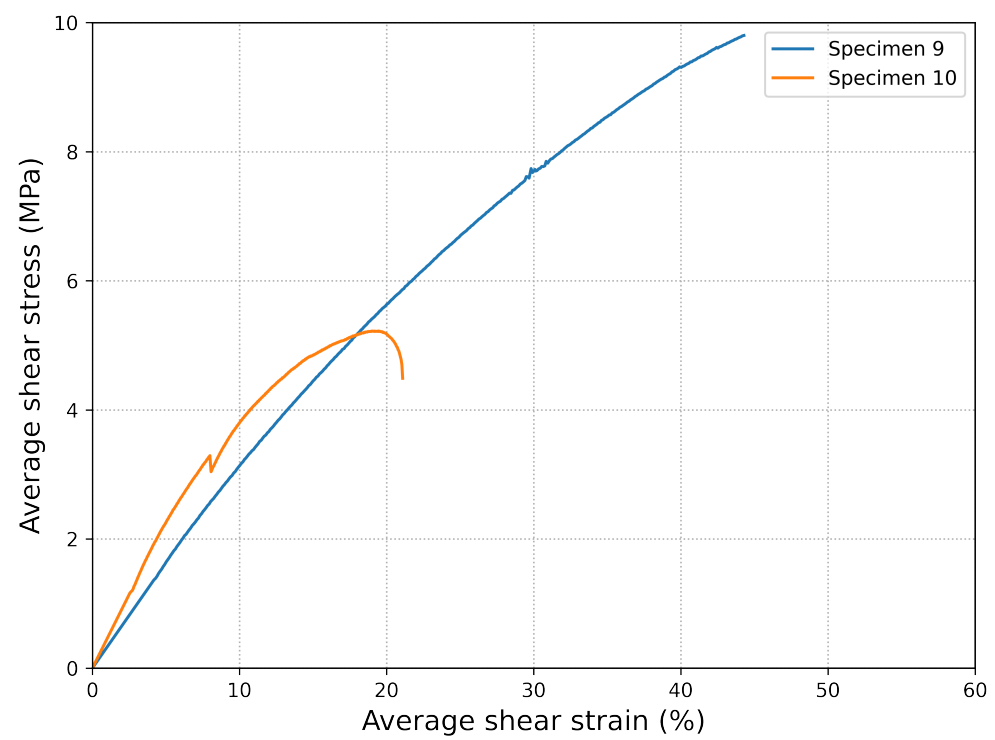




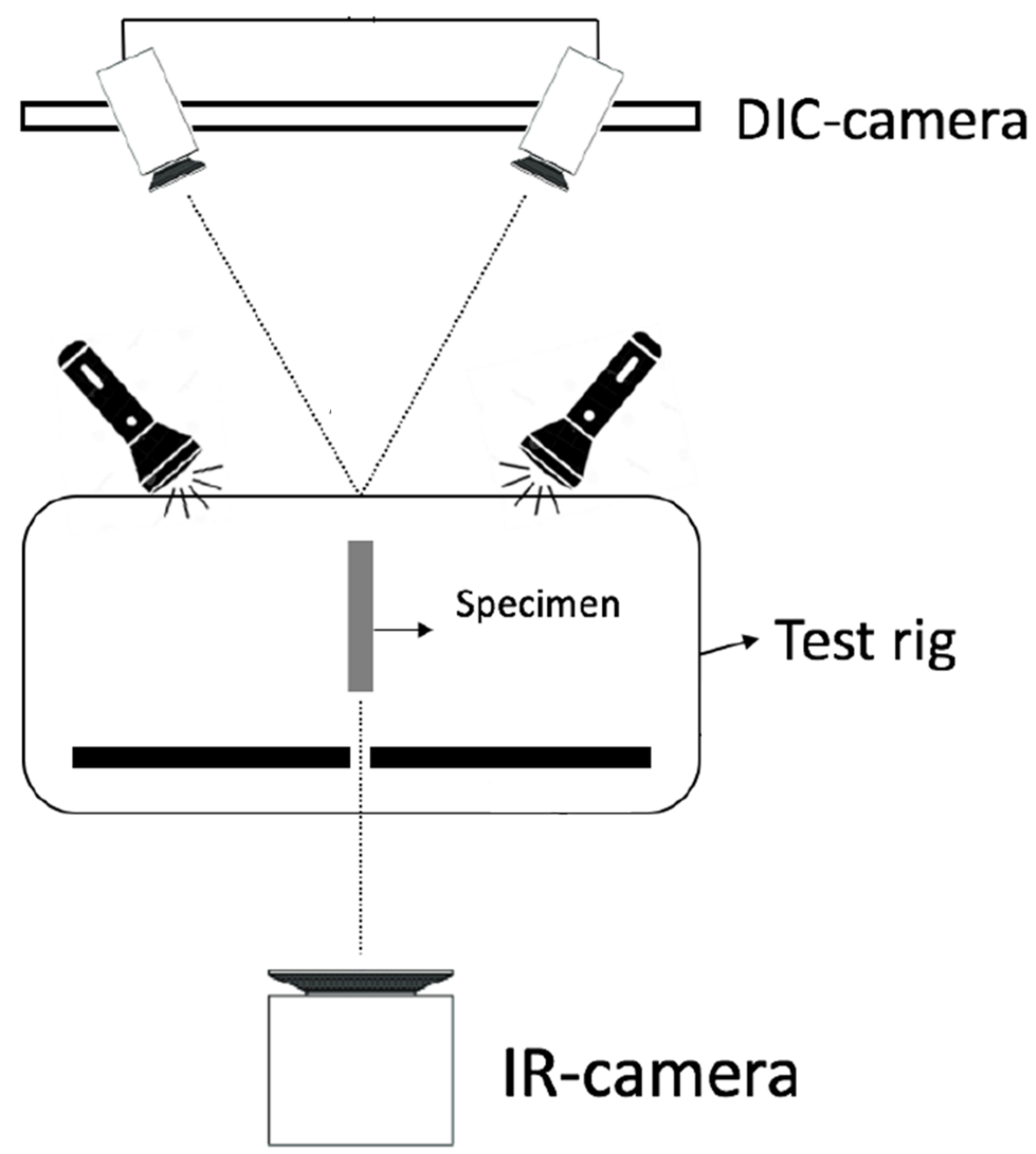



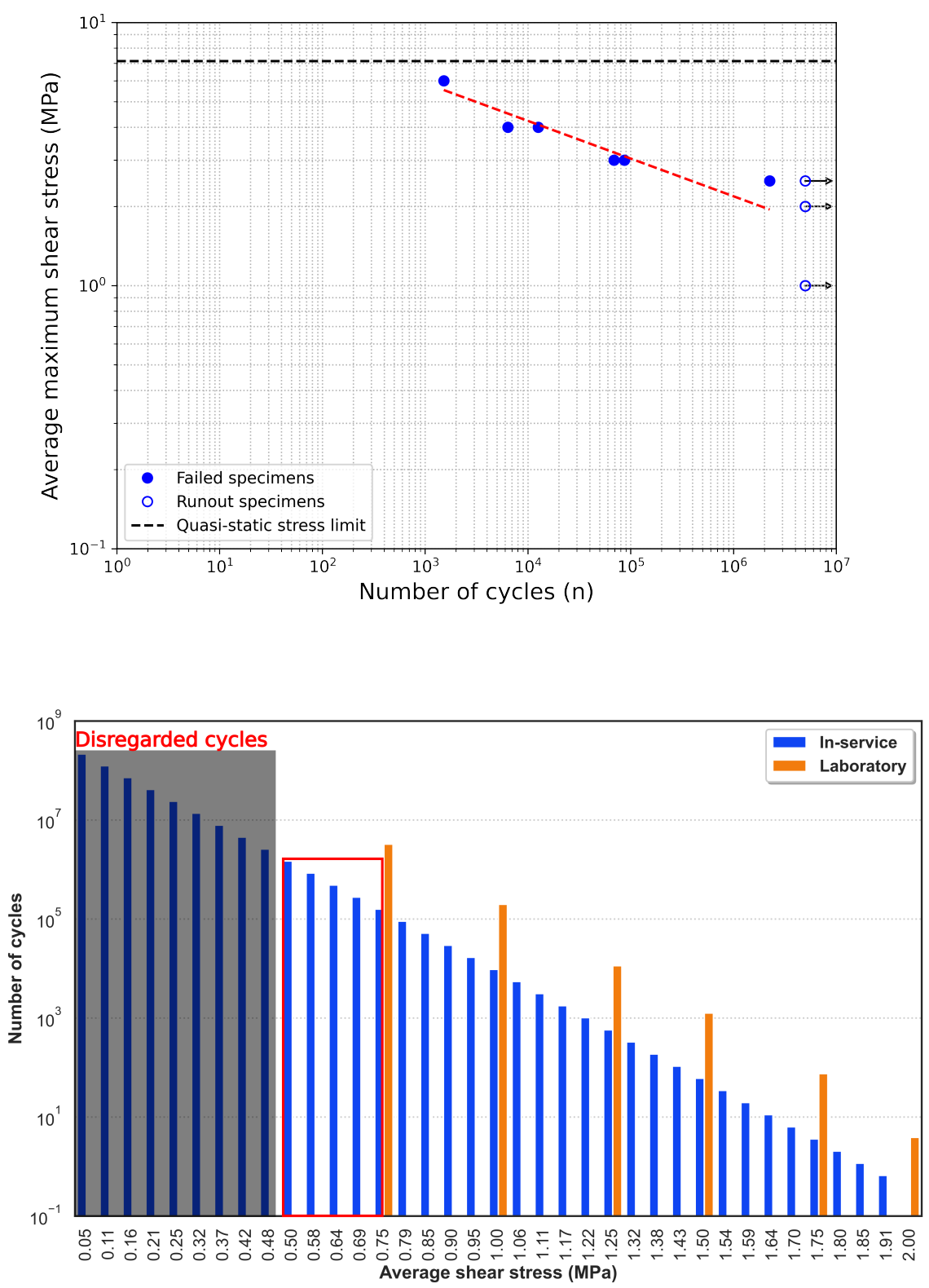